http://jmscr.igmpublication.org/home/ ISSN (e)-2347-176x ISSN (p) 2455-0450

crossref DOI: https://dx.doi.org/10.18535/jmscr/v10i2.26

\title{
Haemodynamic alterations while grafting the anterior, lateral and inferior surfaces of heart during off pump coronary artery bypass grafting (OPCABG) surgery in a tertiary care hospital
}

\author{
Authors \\ Harun Ramasami ${ }^{1}$, Surendra Singh Yadav $^{2 *}$ \\ Department of Cardio Thoracic \& Vascular Surgery; Medical College \& Hospital, Kolkata, Kolkata, India \\ *Corresponding Author \\ Surendra Singh Yadav
}

\begin{abstract}
Introduction: The potential benifits of off pump $C A B G(O P C A B G)$ include not only reduced systemic inflammation, coagulopathy, atheroembolism, brain edema, respiratory and other end-organ dysfunction but also more cost-effective resource utilization. However, during OPCABG there is inevitable hemodynamic instability during manual positioning of heart \& mechanical stabilisation.

Materials \& Methods: Over a period of one year, 50 patients undergoing OPCABG, were monitored for significant changes in Central Venous Pressure (CVP), Mean Arterial Pressure (MAP), Mean Pulmonary Arterial Pressure (MPAP) \& Left Ventricular End Diastolic Pressure (LVEDP) during operation at baseline, during manipulation \& shunt introduction, during anastomosis \& after anastomosis.

Results: MAP significantly reduced compared to baseline value $(76 \pm 11.6)$ during manipulation \& shunt introduction in the diagonals $(70 \pm 5.6 ; p<0.045)$, ramus $(70 \pm 5.0 ; p<0.043)$, obtuse marginals $(65 \pm 5.5$; $p<0.029)$ \& the right sided arteries ie.PDA/RCA/PLV $(69 \pm 5.0 ; p<0.038)$. We also found that while grafting the ramus \& the OMs, there was significant rise in CVP during positioning of heart \& shunt introduction. Interestingly, while doing the same manouver, significant rise in MPAP was witnessed only for the OMs and none others.

Conclusion: Judicious handling of heart during positioning \& mechanical stabilization for grafting can minimize the inevitable haemodynamic changes that occur during OPCABG. Monitoring the haemodynamic parameters continuously help us in modifying our mechanical \& anaesthetic adjustment strategies preventing unnecessary use of cardio pulmonary bypass.
\end{abstract}

\section{Introduction}

Coronary artery disease is a major concern in the modern lifestyle. The management of coronary artery disease has been evolved a lot from medical management to surgical intervention. Initially the revascularization process started with $\mathrm{CABG}$ with on pump with cardioplegic arrest. Later on with on-pump beating heart. Recently, coronary artery bypass grafting (CABG) on the beating heart, without the use of a pump oxygenator (off-pump CABG or OPCABG), has been offered as an alternative to the standard on-pump technique. In the off-pump technique, for the grafting of the circumflex artery and posterior descending artery branches through sternotomy, anterior displacement of the beating heart needs to occur. 
This often causes hemodynamic compromise ${ }^{1,2}$. To counter this, many of the maneuvers performed during beating heart surgical procedures (volume loading, Trendelenburg, right hemisternum elevation, release of restricting right pericardium) are primarily aimed at aiding the right heart. Thus, it is important to analyze the hemodynamic changes during the periods when the heart is tilted and find a more effective way to access the circumflex artery and posterior descending artery without hemodynamic compromise. The purpose of this study is to analyze the hemodynamic changes in patients whose hearts are tilted during grafting of the anterior, lateral and inferior surfaces of the heart.

\section{Aims \& Objectives}

The objectives of this study was to monitor the intraoperative haemodynamic changes in a cohort of patients presenting with coronary artery disease that were going to get revascularized on beating heart \& thus add to our existing knowledge.

\section{Materials and Methods}

This study was conducted between $1^{\text {st }}$ October $2014 \& 30^{\text {th }}$ September 2015, in the CTVS Department of Medical College \& Hospital Kolkata. We included all patients with single, double or triple vessel disease with or without left main disease, irrespective of their age, gender, risk factors and ejection fraction. We excuded emergency CABGs, those who required Cardio Pulmonary Bypass (CPB) during surgery \& those who had associated valvular or congenital cardiac diseases. We had 50 patients \& all of them were operated upon by consultant surgeons of reasonably good competencies using standard techniques. Every patient had a Swan-Ganz catheter inserted through the IJV \& an arterial catheter in radial/ femoral artery for assessing haemodynamics. A separate CVP line was put in for drug \& fluid administration. We measured Central Venous Pressure (CVP), Mean Arterial Pressure (MAP), Mean Pulmonary Arterial Pressure (MPAP) \& Left Ventricular End
Diastolic Pressure (LVEDP) in our patients while grafting the anterior, lateral \& inferior surfaces of the heart. These measurements were noted separately during

1. Cardiac positioning \& shunt introduction;

2. During anastomosis with shunt;

3. After completed anastomosis.

We used pericardial silk stay sutures \& Octopus stabilizer with a wall suction of $250 \mathrm{mmHg}$ to position heart for anastomosis.

\section{Statistical Analysis}

Statistical calculations were made with SPSS 8 for Windows (SPSS, Chicago, IL), and $p$ values less than 0.05 were regarded as statistically significant. Comparison of baseline data with the data obtained during the procedure was done using Students Paired T test.

\section{Results}

Age distribution in our study was from 32 to 84 years with mean age of $50 \pm 7.2$. We had only 4 female patients. $70 \%$ of our patients were smokers, $40 \%$ were diabetic, $52 \%$ were hypertensive \& $84 \%$ were dyslipidemic. 28 of our patients presented with acute myocardial infarction, 7 presented with unstable angina \& 15 presented with chronic stable angina. On Echocardiography 36 patients had regional wall motion abnormality (RWMA) and 14 patients had no RWMA. We found cardiac chamber size enlarged in 26 patients. Ejection Fractions varied from $30 \%$ to $60 \%$. In our study majority of patients had triple vessel disease (29), 8 patients had double vessel disease, 2 patients had single vessel disease and 14 patients had Lt. main disease along with combination of other vessel disease. All 50 patients got Left anterior descending artery grafts, 23 Diagonal grafts, 10 Ramus grafts, 35 obtuse marginal and 34 grafts were done in right territory (posterior descending artery -PDA; right coronary artery - RCA \& posterior left ventricular artery-PLV).

As depicted in Table-1, during the Left anterior descending (LAD) artery grafting the CVP, MAP, 
MPAP \& LVEDP did not show any significant haemodynamic changes during positioning of heart, during anastomosis with shunt as well as after it's completion. However the MAP significantly reduced during manipulation \& shunt introduction in the diagonals, ramus, obtuse marginals (OM) \& the right sided arteries (PDA/RCA/PLV). We also found that while grafting the ramus \& the OMs, there was significant rise in CVP during positioning of heart \& shunt introduction. Interestingly, while doing the same manouver, significant rise in MPAP was witnessed only for the OMs and none others. None of the cases showed notable changes in LVEDP at any point. We also appreciated that use of intracoronary shunts during anastomosis avoided significant haemodynamic compromise and hence is a very standard and safe practice.

Table -1: Haemodynamic alterations while grafting the anterior, lateral \& inferior surfaces of heart

\begin{tabular}{|c|c|c|c|c|c|}
\hline $\begin{array}{l}\text { Territory } \\
\text { grafted }\end{array}$ & $\begin{array}{c}\text { Parameters } \\
(\mathrm{mmHg})\end{array}$ & Baseline & $\begin{array}{l}\text { During manipulation } \\
\text { \& shunt introduction }\end{array}$ & $\begin{array}{l}\text { During anastomosis } \\
\text { with shunt }\end{array}$ & $\begin{array}{c}\text { After } \\
\text { anastomosis }\end{array}$ \\
\hline \multirow[t]{4}{*}{ LAD } & 1.CVP & $9 \pm 1.7$ & $10 \pm 1.5$ & $9.9 \pm 1.3$ & $9.5 \pm 1.5$ \\
\hline & 2.MAP & $76 \pm 11.6$ & $73 \pm 5.3$ & $75 \pm 7.8$ & $80.2 \pm 4.6$ \\
\hline & 3.MPAP & $16 \pm 2.0$ & $15 \pm 3.0$ & $16.4 \pm 1.5$ & $16.7 \pm 1.6$ \\
\hline & 4.LVEDP & $14 \pm 1.5$ & $14.6 \pm 0.8$ & $15 \pm 1.4$ & $14.2 \pm 1.3$ \\
\hline & & & & & \\
\hline \multirow[t]{4}{*}{ Diagonal } & 1.CVP & $9 \pm 1.7$ & $10 \pm 1.4$ & $9.5 \pm 1.2$ & $9.1 \pm 1.2$ \\
\hline & 2.MAP & $76 \pm 11.6$ & $\begin{array}{c}70 \pm 5.6 \\
\mathbf{p}<\mathbf{0 . 0 4 5}\end{array}$ & $75 \pm 6.6$ & $78 \pm 6.0$ \\
\hline & 3.MPAP & $16 \pm 2.0$ & $14 \pm 2.6$ & $16.1 \pm 1.1$ & $15.7 \pm 1.6$ \\
\hline & 4.LVEDP & $14 \pm 1.5$ & $14.7 \pm 1.0$ & $14.8 \pm 1.2$ & $14.9 \pm 1.0$ \\
\hline \multirow[t]{4}{*}{ Ramus } & 1.CVP & $9 \pm 1.7$ & $\begin{array}{l}12.5 \pm 1.8 \\
\mathbf{p}<\mathbf{0 . 0 4 8}\end{array}$ & $10 \pm 1.2$ & $8.8 \pm 1.2$ \\
\hline & 2.MAP & $76 \pm 11.6$ & $\begin{array}{c}70 \pm 5.0 \\
\mathbf{p}<\mathbf{0 . 0 4 3}\end{array}$ & $73 \pm 6.7$ & $76.5 \pm 5.8$ \\
\hline & 3.MPAP & $16 \pm 2.0$ & $14 \pm 2.4$ & $15.4 \pm 1.6$ & $16.3 \pm 1.1$ \\
\hline & 4.LVEDP & $14 \pm 1.5$ & $14.4 \pm 1.2$ & $14.1 \pm 1.6$ & $14.3 \pm 1.5$ \\
\hline \multirow[t]{4}{*}{$\mathrm{OM}$} & 1.CVP & $9 \pm 1.7$ & $\begin{array}{l}12.5 \pm 2.6 \\
\mathbf{p}<\mathbf{0 . 0 4 5}\end{array}$ & $10.2 \pm 1.3$ & $9.9 \pm 1.5$ \\
\hline & 2.MAP & $76 \pm 11.6$ & $\begin{array}{c}65 \pm 5.5 \\
\mathbf{p}<\mathbf{0 . 0 2 9}\end{array}$ & $75.1 \pm 6.4$ & $78.2 \pm 6.2$ \\
\hline & 3.MPAP & $16 \pm 2.0$ & $\begin{array}{l}18.4 \pm 3.4 \\
\mathbf{p}<\mathbf{0 . 0 4 5}\end{array}$ & $15.8 \pm 1.5$ & $16.8 \pm 2.0$ \\
\hline & 4.LVEDP & $14 \pm 1.5$ & $14.3 \pm 1.0$ & $14.6 \pm 1.3$ & $14.0 \pm 1.2$ \\
\hline \multirow{4}{*}{$\begin{array}{l}\text { PDA/RCA/ } \\
\text { PLV }\end{array}$} & 1.CVP & $9 \pm 1.7$ & $10.6 \pm 0.5$ & $10.6 \pm 1.0$ & $10.2 \pm 1.6$ \\
\hline & 2.MAP & $76 \pm 11.6$ & $\begin{array}{c}69 \pm 5.0 \\
\mathbf{p}<\mathbf{0 . 0 3 8}\end{array}$ & $73.1 \pm 4.6$ & $77.6 \pm 6.2$ \\
\hline & 3.MPAP & $16 \pm 2.0$ & $16.5 \pm 2.4$ & $16.1 \pm 1.0$ & $16.3 \pm 1.0$ \\
\hline & 4.LVEDP & $14 \pm 1.5$ & $14.7 \pm 1.6$ & $14.9 \pm 1.2$ & $14.0 \pm 1.5$ \\
\hline
\end{tabular}




\section{Discussions}

Concern regarding adverse effects of cardiopulmonary bypass have led to the current widespread application of off-pump techniques for CABG surgery. However the use of mechanical stabilizer and manual handling of the heart during OPCAB has some disadvantages especially haemodynamic compromise.

Our study enriched the present knowledge of the haemodynamic changes occurring while grafting the different surfaces of the heart. We observed four haemodynamic parameters namely CVP, MAP, MPAP \& LVEDP in different timings during OPCAB surgery.

All our 50 patients got Left anterior descending artery grafts, 23 got Diagonal grafts, 10 Ramus grafts, 35 obtuse marginal and 34 grafts were done in right territory (posterior descending artery /PDA-23; right coronary artery /RCA- 8 \& posterior left ventricular artery/PLV- 3).

In our study the central venous pressure was significantly increased during manipulation \& shunt introduction during ramus grafting $(12.5 \pm 1.8$ compared with the baseline value $9 \pm 1.7$ with the significance of $\mathrm{p}<0.048)$, and during obtuse marginal grafting $(12.5 \pm 2.6$ compared with baseline $9 \pm 1.7$, with the significance of $p<0.045$ ). Regarding CVP this study corroborates with M.Yeatman et $\mathrm{al}^{3}$, where they concluded that the CVP significantly increased during manipulation and shunt introduction. However this study not corroborating with Y.L. Kwak et $\mathrm{al}^{4}$ study, where they showed the CVP significantly increased during anastomosis of all the territories.

The mean arterial pressure (MAP) was significantly decreased during manipulation and shunt introduction of diagonal $70 \pm 5.6$ with the $\mathrm{p}$ value $<0.045$, ramus $70 \pm 5.0$ with the $p$ value $<0.043$, obtuse marginal $65 \pm 5.5$ with the $\mathrm{p}$ value $<0.029$, and in the Right territory $69 \pm 5.0$ with $\mathrm{p}$ value $<0.038$; compared with the baseline value $76 \pm 11$.6. This significance corroborates with $\mathrm{M}$. Yeatman et al ${ }^{3}$ study, in which they showed the significant decrease during manipulation \&stabilization. However this study is not corroborating with Quo Bao Do et $\mathrm{al}^{5}$ study, where they concluded the MAP was maintained throughout the anastomosis of all coronary arteries.

The mean pulmonary artery pressure (MPAP) was significantly increased $18.4 \pm 3.4$ with the $\mathrm{p}$ value $<0.045$ compared with the base value $16 \pm 2.0$ during manipulation and shunt introduction in the obtuse marginal artery. However this study does not corroborates with Quo Bao Do et $\mathrm{al}^{5}$ study, where they found that, the MPAP significantly increased during the LAD grafting and $M$. Yeatman et $\mathrm{al}^{3}$ studied that, significant increase in grafting of the PDA.

However, Left ventricular end diastolic pressure (LVEDP) did not show any significant change during the operations. Our finding regarding LVEDP does not corroborate with the Mathison et $\mathrm{al}^{6}$, in that they found that the LVEDP significantly increased during the manipulation of heart while grafting the circumflex artery. Absence of significant change in LVEDP in our study may be due to the fact that the measurement of LVEDP was an indirect measurement. In our study we measured pulmonary capillary wedge pressure (ie. Mean Left Atrial pressure) as LVEDP. This might be a reason to get the insignificant $p$ values for this parameter.

\section{Conclusion}

Our study contributed to the present knowledge about the inevitable changes in haemodynamics during OPCAB. Careful monitoring and management of these hemodynamic variables are warranted to avoid conversion to on-pump technique.

We witnessed that the central venous pressure showed significant change during the manipulation of the heart while grafting of it's lateral surfaces. There was significant decrease in the mean arterial pressure during manipulation of the heart during all the territories (anterior, lateral and inferior surfaces). The mean pulmonary artery pressure was however, significantly increased only with the manipulation during grafting of the 
lateral surface of the heart. However the left ventricular end diastolic pressure did not show any significant change in our study.

Finally all these haemodynamic changes are reflected by the reduced diastolic filling of the chambers (especially of the ventricles) by the direct application of the octopus stabilizer and by manual handling of the heart. Compression of the $\mathrm{RV}$ more than the LV during manipulation \& obstruction of LV outflow by mechanical stabilizers specially during ramus grafting are notorious for causing altered haemodynamics. So by soft handling of the heart \& judicious placement of stabilizers during OPCAB we can definitely reduce the significant haemodynamic changes which are bound to happen otherwise.

\section{References}

1. Porat E, Sharony R, Ivry S, et al. Hemodynamic changes and right heart support during vertical displacement of the beating heart. Ann Thorac Surg 2000; 69:1188-91.

2. Gru" ndeman $P$, Borst $C$, van Herwaarden JA, Mansvelt Beck HJ, Jansen EWL. Hemodynamic changes during displacement of the beating heart by the Utrecht Octopus method. Ann ThoracSurg 1997;63:S88 -92.

3. M. Yeatman, M. Caputo, P. Narayan, A. Kumar Ghosh, R. Ascione, I. Ryder, and G. D. Angelini. Intra coronary shunts reduce transient intraoperative myocardial dysfunction during off pump coronary operations. Ann. Thorac. Surg., May 1, 2002; 73(5): 1411-1417.

4. Kwak YL, Oh YJ, Jung SM, Yoo KJ, Lee JH, Hong YW Change in right ventricular function during off-pump coronary artery bypass graft surgery.. Eur J Cardiothorac Surg. 2004 Apr;25(4):572-7.
5. Q.-B. Do, C. Goyer, O. Chavanon, P. Co; 21 couture, A. Denault, and R. Cartier Haemodynamic changes during off-pump CABG surgery Eur J Cardiothoracic Surg, March 1, 2002; 21(3): 385-390.

6. Mathison M, Edgerton JR, Horswell JL, Akin JJ, Mack MJ. Analysis of haemodynamic changes during beating heart surgical procedures. Ann Thoracic Surg. 2000;70: 1355-1361. 